\title{
Echovirus encephalitis and myositis in primary immunoglobulin deficiency
}

\author{
A. D. B. WEBSTER, J. H. TRIPP, A. R. HAYWARD, A. D. DAYAN, R. DOSHI, E. H. MACINTYRE, \\ AND D. A. J. TYRRELL
}

From The Hospital for Sick Children and Institute of Child Health, London, and the Clinical Reasearch Centre, Northwick Park Hospital, Harrow, Middlesex

SUMMARY Two children are described with primary hypogammaglobulinaemia and encephalitis associated with echovirus infection. One also developed a condition resembling dermatomyositis which improved after he was given infusions of plasma containing antibody to the echovirus. Although both died of their encephalitis, the course of the brain disease in one of them may have been prolonged by treatment with specific antibody. These cases, together with another briefly mentioned case in an adult with congenital hypogammaglobulinaemia and echovirus infection, indicate that these patients are particularly susceptible to echoviruses.

Patients with immunoglobulin deficiency usually recover uneventfully from childhood virus infections such as mumps, measles, and varicella. However, there is evidence that viruses may occasionally cause encephalitis in such children (Hanissian et al., 1972; Linneman, 1973). We describe 2 boys with probable $\mathrm{X}$-linked hypogammaglobulinaemia who developed central nervous system disease associated with an echovirus infection. One of them also had a myositis.

\section{Methods}

Lymphocyte studies. B lymphocytes were recognised by surface immunoglobulin using an immunofluorescence technique, and $\mathrm{T}$ lymphocytes by sheep red blood cell rosette formation (E rosettes). Lymphocyte response to phytohaemagglutinin (PHA) was measured over a 72-hour incubation by radioactive thymidine uptake during the final 16 hours of culture. Results are expressed as stimulation index.

Delayed hypersensitivity skin tests. Purified protein derivative of tubercle bacillus (PPD) (Ministry of Agriculture) 10 and 100 units, and Candida albicans $1 \%$ (Bencard) both $0.1 \mathrm{ml}$ intradermally. Dinitrochlorobenzene (DNCB) $0.1 \mathrm{ml}$ of a $5 \%$ sensitizing dose followed by challenge with $0 \cdot 1 \% 7$ or more days later.

Migration inhibition. The inhibition of migration from capillary tubes over 16 hours of buffy coat cells by

Received 8 June 1977 three concentrations of echovirus 11 vaccine was measured. Control wells contained supernatant from MRC5 fibroblasts. Results were expressed as:

$$
100-\left(\frac{\text { migration of cells with vaccine }}{\text { migration of cells without vaccine }} \times 100\right)
$$

Isolation and identification of viruses. Viruses were cultured using human embryonic lung fibroblasts (MRC5) and identified by the typical cytopathic effect and by specific antisera.

Preparation of material for therapy (Case 1). Plasma with an anti-echovirus 11 haemagglutination inhibition titre of $>1: 40$ was obtained from volunteer blood donors, from patients recovering from infections with echovirus 11, and from the patient's mother after a series of injections of a formalin inactivated echovirus 11 vaccine given with pertussis vaccine (Burroughs Wellcome). This vaccine was prepared by propagating the virus isolated from the patient on MRC5 fibroblasts in a special laboratory and processing the culture fluid as for polio vaccine. A batch of commercial gammaglobulin with an echovirus 11 antibody titre of 1:80 and $300 \mathrm{ml}$ of hyperimmune horse serum containing echovirus 11 antibody at a titre of 1:1280 were also used.

\section{Case reports}

Case 1. Hypogammaglobulinaemia was diagnosed at 18 months after he had suffered from pneumococcal meningitis, recurrent chest infections, and polio- 
myelitis which left him paralysed below the waist. He had since remained in relatively good health on regular weekly gammaglobulin injections. His disease was clearly familial since his brother and a son of a maternal aunt have hypogammaglobulinaemia with absence of circulating B lymphocytes. 4 of the mother's brothers also died in infancy or early childhood of infections.

At 11 years he developed drowsiness, headache, and tremor of the hands. One month later he was admitted for investigation of a possible cerebral abscess and, during a cerebral arteriogram (normal), developed status epilepticus and remained in a trance-like state for almost 3 weeks from which he could only be roused to obey simple commands. During this time he developed a painful fluctuating polyarthritis affecting the joints of the upper limbs and ankles. When examined one month later there was muscle rigidity on passive movement of the upper arms and marked intention tremor. The ankles were also swollen but the rest of his paralysed legs were unaffected. There was tense oedema of the subcutaneous tissue of the upper and lower arms and a transient erythematous rash over the right biceps region. He was thin and wasted.

Investigations. Microcytic, hypochromic anaemia (Hb 9.6 g/dl). Serum creatine phosphokinase $11 \mathrm{IU} / 1$ (normal 5-80). Serum immunoglobulins grossly reduced, $\operatorname{IgG} 19, \operatorname{IgA}<12$, and $\operatorname{IgM}<5 \mathrm{IU} / \mathrm{ml}$; blood lymphocyte count $3.2 \times 10^{9} / 1$; lymphocyte response to PHA was low (stimulation index 24, normal $>60$ ); delayed hypersensitivity skin tests to PPD, Candida, and DNCB were all negative but became positive 7 months later. Leucocyte migration inhibition to echovirus 11 vaccine was positive on two separate occasions ( $26 \%$ and $35 \%$ inhibition).

Repeated samples of CSF (normal pressure) contained raised cells and protein. In the first there were white cells $425 / \mathrm{mm}^{3}\left(0 \cdot 425 \times 10^{9} / 1\right)(95 \%$ mononuclear cells), and $3 \cdot 1 \mathrm{~g} / 1$ protein with normal sugar. Bacteriological cultures were negative but echovirus 11 was identified in the first sample cultured (4 months after the onset of the illness) and in 8 of the 16 subsequent samples. No viral antigen was detected in cells from the CSF by immunofluorescence using horse anti-echovirus 11 antisera.

A biopsy of skin, subcutaneous tissue, and muscle taken from the right forearm showed a predominantly mononuclear cell infiltrate in muscle with destruction of some muscle fibres (Fig.) and in the connective tissue around the small blood vessels. Immunofluorescence failed to show viral antigen in the muscle tissue and virus cultures were negative. Separated blood lymphocytes cultured with a homogenate of muscle tissue showed no increased uptake of tritiated thymidine after 6 days (M. M. Esiri).

Progress. There was rapid improvement in the subcutaneous oedema, level of consciousness, and tremor of the upper limbs after he was given hyperimmune plasma. 61 hyperimmune plasma, $6 \mathrm{U}$ transfer factor (equivalent to 31 blood), multiple BCG immunisations, and a course of gammaglobulin injections containing echovirus 11 antibody were given over the next 10 months. He needed anticonvulsants to control recurrent epilepsy and a Spitz-Holter valve was inserted for hydrocephalus. Despite these problems he was able to return to school intermittently. 20 months after onset, the

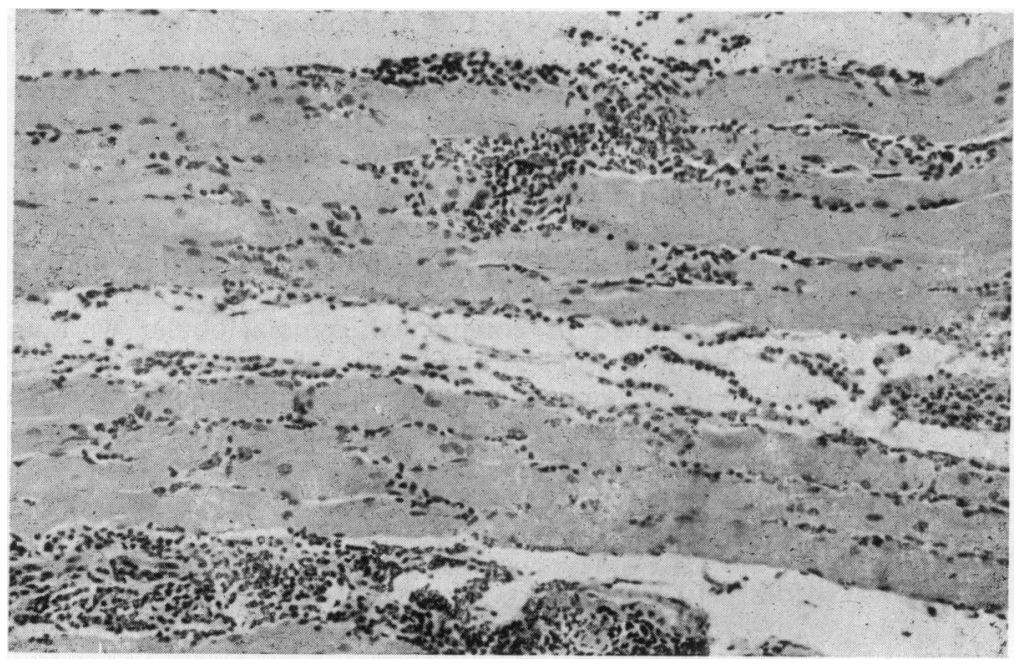

Fig. Case 1. Muscle biopsy showing mononuclear cell infiltration and some muscle fibre necrosis. (Haematoxylin and eosin $\times 150$.) 
CSF protein rose to $9 \mathrm{~g} / 1$ and his condition deteriorated. He was then given an infusion of maternal blood and bone marrow cells, a course of injections of hyperimmune horse serum, and a further $8 \mathrm{U}$ hyperimmune plasma. In spite of a further temporary improvement, his condition deteriorated and he died suddenly with failure of the respiratory centre 28 months after his first admission. At no time was echovirus 11 antibody detected in the CSF although a small amount of IgG immunoglobulin $(0.05 \mathrm{~g} / \mathrm{l})$ appeared after plasma therapy.

Necropsy findings. The thymus was normal apart from absence of Hassall's corpuscles. The peripheral and central lymph nodes contained no germinal centres or plasma cells but the paracortical regions showed normal cellularity. The malpighian bodies in the spleen were poorly developed and only small aggregates of lymphoid cells were present in the appendix where there were no fully formed follicles.

The meninges over the cerebral hemispheres, in the posterior fossa, and throughout the spinal column were thickened and tightly adherent with obliteration of the subarachnoid space by a mononuclear cell inflammatory infiltrate. The lateral and 3 rd ventricles were moderately dilated with granular thickening of the ependyma and obliteration of the aqueduct. There were scattered demarcated scars on the surface of the cerebral cortex which did not involve the underlying white matter. Histology of these areas showed astrocytic proliferation, microcalcification, and perivascular lymphocyte infiltration. There were similar changes in the central grey matter, dentate nuclei, and olives. The cerebellum was also affected with loss of Purkinje and granular cells with an increase in Bergmann glia. There was loss of cells in the anterior horns and posterior root ganglia of the lower thoracic and lumbar spine associated with a perivascular mononuclear cell infiltrate. No viruses were isolated from the brain or from culture supernatants of brain tissue. Echovirus 11 antigen was not demonstrated in brain by immunofluorescence.

Case 2. A nonidentical twin born to unrelated parents at 36 weeks' gestation, weighing $2.5 \mathrm{~kg}$. There was no relevant family history. From the age of 3 months he had frequent upper and lower respiratory tract infections, two episodes of otitis media, and an axillary abscess. At 2 years he had a right upper lobe pneumonia, suddenly became ataxic, and developed a trance-like state. On admission he was pale and thin, his weight and head circumference being on the $3 \mathrm{rd}$ centile and height on the 25th centile. There was lid retraction, dilated unreacting pupils, marked truncal and limb ataxia, brisk symmetrical deep tendon reflexes, and bilateral extensor plantar responses.

Investigations. $\mathrm{Hb} \quad 11 \cdot 2 \mathrm{~g} / \mathrm{dl}$; mild neutropenia $\left(1.6 \times 10^{9} / 1\right)$ with a normal lymphocyte count $\left(2 \cdot 2 \times 10^{9} / 1\right)$. Serum immunoglobulins were grossly reduced $\operatorname{IgG}<12, \operatorname{IgA}<12$, and $\operatorname{IgM} 37 \mathrm{IU} / \mathrm{ml}$; lymphocyte response to PHA was low (stimulation index 15), delayed hypersensitivity skin tests to Candida were negative. Examination of spleen lymphocytes obtained at necropsy showed absence of surface IgG and IgM, though most had surface IgG (after replacement therapy). $21 \%$ of cells formed $\mathrm{E}$ rosettes. There was evidence of inappropriate antidiuretic hormone secretion.

Left carotid and vertebral angiograms were normal. Electroencephalogram showed widespread slow wave activity. CSF was under normal pressure and contained red blood cells $495 / \mu 1$, white blood cells $0.016 \times 10^{9} / 1$, protein $0.87 \mathrm{~g} / 1$, and normal glucose. No viruses or bacteria were isolated from the CSF. Blood culture grew E.coli. A right frontal brain biopsy was performed on the third day after admission and echovirus type 25 was cultured by two separate laboratories.

Progress. There was a short period of apnoea, without apparent anoxia, after a generalised convulsion which was treatea with intravenous diazepam. 12 hours later he assumed a decerebrate posture but continued to respond to auditory and visual stimuli. Fluids were restricted and he was given dexamethasone, human gammaglobulin, gentamicin, and cephaloridine. His clinical condition remained unaltered for the next 2 weeks and then deteriorated with frequent apnoeic episodes and convulsions. He died 5 weeks after the onset of his pneumonia.

Necropsy findings. The spleen was of normal size but the malpighian bodies were poorly developed. The thymus was small and moderately hypocellular but contained numerous Hassall's corpuscles. The peripheral lymph nodes showed an increase in cellularity of the paracortical region but contained no germinal centres or plasma cells.

There was extensive antemortem cerebral sinus thrombosis. The meninges and brain were grossly normal apart from some shrinkage of the medulla. Sections of the brain stem showed a severe subacute encephalitis with marked mononuclear perivascular cuffing, neuronal loss in the cranial nerve nuclei, degenerating nerve cells, and neuronophagia with astrocytic reaction in the pons and medulla. The inflammatory process was less severe in the thalamus and basal ganglia with only mild changes in the 
cerebral hemispheres, the cerebellum, and cervical cord.

\section{Discussion}

Both patients had hypogammaglobulinaemia which may have been of the X-linked type. The family history in Case 1 was suggestive, but the absence of thymic Hassall's corpuscles is not usual in this condition. Another atypical feature was that Case 2 made some IgM. Both had depressed lymphocyte transformation to PHA and depressed delayed hypersensitivity skin reactions when initially tested. However, these defects were probably secondary in Case 1 since these returned to normal after his general condition had improved. The finding of $T$ lymphocytes in the spleen at necropsy, together with the normal appearance of the lymph node paracortical region indicates that neither of these patients had a significant primary defect in cellular immunity. Echovirus 11 inhibited the migration of leucocytes in Case 1, which may be evidence of cell-mediated immunity. However, since the migration inhibition tests were performed after treatment with hyperimmune serum, it is possible that the inhibition was mediated by cytophilic antibody (Ortiz-Ortiz et al., 1974).

Dayan (1971) found evidence of viral encephalitis in the brains of 9 of 23 infants dying with severe combined immunodeficiency. However, only a few cases of encephalitis have been described in patients with hypogammaglobulinaemia and intact cellular immunity. Lyon and Griscelli (1973) reviewed 8 such patients and suggested an autoimmune pathogenesis although measles viral antigen was found in the brain of one of these patients (Hannissian et al., 1972). Linneman et al. (1973) described 2 patients in whom Herpes simplex virus was isolated from brain tissue; echovirus 2 was also isolated from one of these patients. Ziegler and Penny (1975) described a boy with $\mathrm{X}$-linked agammaglobulinaemia, amyloid and fatal chronic echovirus type 30 meningoencephalitis.

Myositis similar to that in Case 1 has been described in X-linked agammaglobulinaemia (Janeway et al., 1956; Gotoff et al., 1972). It differs from typical dermatomyositis in the normal level of creatine phosphokinase and the absence of sensitised circulating lymphocytes to autologous muscle tissue in Case 1 (Esiri et al., 1973). The skin manifestations were also clinically mild. No virus was isolated from the muscle biopsy but there was dramatic improvement in the muscle disease after treatment with plasma containing antibody to the virus. We have recently isolated echovirus 3 from the CSF of another 21-year-old patient with probable X-linked agammaglobulinaemia. He had tense subcutaneous oedema and erythema of the legs with electromyographic, but not histological evidence of myositis. There were no signs or symptoms of neurological disease despite raised cells and protein in the CSF.

Children with X-linked agammaglobulinaemia seem more prone to chronic viral brain disease than those with the adult onset type of primary hypogammaglobulinaemia. This may reflect a total inability to produce local antibody within the central nervous system in congenital type cases, which usually have absence of circulating B lymphocytes. Perhaps patients with the adult onset type retain the ability to make some antibody locally in the central nervous system by analogy with the finding of immunoglobulin-containing cells in the gastrointestinal tract of these patients (Broom et al., 1975). Adults may also have met most of the neurotropic viruses before becoming hypogammaglobulinaemic and have retained some specific immunity. Case 1 developed echovirus infection while on gammaglobulin therapy, presumably because of lack of antibodies to this serotype in the pooled human gammaglobulin. This is probably due to the continual variation of the prevalent echovirus serotype in the population (Public Health Laboratory Service, 1974). Gammaglobulin prepared more than a year before use may consequently fail to protect patients with hypogammaglobulinaemia against echoviruses.

Echovirus meningoencephalitis and myositis should be suspected when neurological or 'dermatomyositic' signs occur in patients with hypogammaglobulinaemia, especially when there are raised protein and cells in the CSF. As virus culture of CSF was only intermittently positive in 2 of the 3 patients, it may be necessary to do at least three lumbar punctures. Culture of a brain biopsy may also be indicated.

We thank Dr E. M. Brett for permission to study Case 2, and Dr M. Erdohazi for the neuropathological report; Drs T. E. Davies, T. E. Cleghorn, J. V. S. Pether, R. M. Lowenthal, V. Cossart, and A. R. Fodor for supplying hyperimmune serum and immunoglobulin; Mr J. Parry and Mrs P. K. Brown for the vaccine; and Dr G. L. Asherson and Professor J. F. Soothill for discussion and advice.

\section{References}

Broom, B. C., De La Concha, E. G., Webster, A. D. B., Loewi, G., and Asherson, G. L. (1975). Dichotomy between immunoglobulin synthesis by cells in gut and blood of patients with hypogammaglobulinaemia. Lancet, 2 , 253-256.

Dayan, A. D., (1971). Chronic encephalitis in children with severe immunodeficiency. Acta Neuropathologica, 19, 234-241. 
Esiri, M. M., MacLennan, I. C. M., and Hazelman, B. L. (1973). Lymphocyte sensitivity to skeletal muscle in patients with polymyositis and other disorders. Clinical and Experimental Immunology, 14, 25-35.

Gotoff, S. P., Smith, R. D., and Sugar, O. (1972). Dermatomyositis with cerebral vasculitis in a patient with agammaglobulinemia. American Journal of Diseases of Children, 123, 53-56.

Hanissian, A. S., Jabbour, J. T., deLamerens, S., Garcia, J. H., and Horta-Barbosa, L. (1972). Subacute encephalitis and hypogammaglobulinemia. American Journal of Diseases of Children, 123, 151-155.

Janeway, C. A., Gitlin, D., Craig, J. M., and Grice, D. S. (1956). 'Collagen disease' in patients with congenital agammaglobulinemia. Transactions of the Association of American Physicians, 69, 93-97.

Linneman, C. C., Jr., May, D. B., Schubert, W. K., Caraway, C. T., and Schiff, G. M. (1973). Fatal viral encephalitis in children with x-linked hypogammaglobulinemia. American Journal of Diseases of Children, 126, 100-103.
Lyon, G., and Griscelli, C. (1973). Chronic encephalitıs in congenital hypogammaglobulinemia. European Study Group on Child Neurology, Kungalv, 1973.

Ortiz-Ortiz, L., Zamacona, G., Garmilla, C., and Arellano, M. T. (1974). Migration inhibition test in leucocytes from patients allergic to penicillin. Journal of Immunology, 113, 993-997.

Public Health Laboratory Service. (1974). Echovirus type II. British Medical Journal, 3, 123.

Ziegler, J. B., and Penny, R. (1975). Fatal ECHO 30 virus infection and amyloidosis in $\mathrm{X}$-linked hypogammaglobulinemia. Clinical Immunology and Immunopathology, 3, 347-352.

Correspondence to Dr A. D. B. Webster, Division of Immunological Medicine, Clinical Research Centre, Watford Road, Harrow HA1 3UJ Middlesex. 